\title{
A institucionalização da interdisciplinaridade e a universidade brasileira
}

Marcel Bursztyn*

o conceito de ciência sobre o qual vivemos não é nem absoluto nem eterno; a ciência evolui [...] uma revolução está a ponto de reagrupar as disciplinas [...] (MORIN, 2004, p. 79)

Resumo O debate sobre o imperativo de uma reforma da Universidade deve ganhar especial importância no Brasil. Questões que estão nas agendas internacionais, como mobilidade no processo de formação e na vida profissional, a empregabilidade e formações generalistas, são sugeridas como parâmetros norteadores. O desenho institucional que sairá da reforma é objeto de reflexão, com destaque para a interdisciplinaridade. A experiência européia é evocada como ponto de referência. O desafio é romper com a cultura conservadora, que orienta os rumos da Universidade.

Palavras-chave Universidade, reforma, mobilidade, empregabilidade, interdisciplinaridade

\begin{abstract}
The debate on the necessary reform of the University is to become more intensive in Brazil. Some of the questions that are in the international agenda, such as mobility in processes of training and in professional life, employability and generalist trainings are suggested as references. The institutional design that will come out of the reform is an object of reflection, with focus on interdisciplinarity. European experience is mentioned as a reference. The challenge is to break the conservatism that guides University.
\end{abstract}

Keywords University, reform, mobility, employability, interdisciplinarity

\section{Introdução}

A Universidade brasileira chega ao século XXI com um conjunto de desafios e de questões profundas a serem resolvidas. A extensa pauta que serve (ou deveria servir) de pano de fundo ao debate da "reforma universitária" inclui temas que refletem particularidades nacionais e questões de uma agenda que é internacional.

No primeiro caso, sobressaem discussões em torno de temas como: quotas para segmentos sociais que historicamente foram excluídos do acesso ao ensino superior; uma nova geografia

\footnotetext{
* Economista Social, mestre em Planejamento Urbano e Regional e doutor em Desenvolvimento Econômico e Social. É professor do Centro de Desenvolvimento Sustentável e do Departamento de Sociologia da Universidade de Brasília. Foi funcionário do CNPq, Presidente da CAPES/MEC e da Fundação de Apoio à Pesquisa do DF.
} 
regional da oferta de cursos; e a indução de novas formações, em consonância com cenários evidentes sobre o futuro de certas profissões e com a identificação de vocações e oportunidades para se chegar a um Projeto Nacional de Desenvolvimento. No segundo caso - a agenda internacional - estão presentes questões como: a duração dos cursos; o financiamento da Universidade; critérios de mensuração e avaliação; articulação entre disciplinas; e enfrentamento de problemas científicos complexos.

Nos seus quase mil anos de existência, a Universidade evoluiu sempre no sentido do geral para o particular. Se, no princípio, o foco era o pensamento filosófico, o direito, a ética e as ciências, incluindo-se a medicina, a evolução se deu inevitavelmente mediante organização em disciplinas. Isso vai ficando evidente sobretudo com o Iluminismo, a Revolução Industrial e a notável transformação experimentada pela Europa, com o contraste entre identidades nacionais marcantes e o imperativo de uma nova globalização, que se impunha com o florescimento da indústria e do comércio, na nova ordem internacional que então se afirmava.

Conforme assinala Bartholo (2001), o projeto de fundação da Universidade de Berlim, proposto por Wilhelm von Humboldt, em 1809, é um caso exemplar, capaz de servir de referência a um debate atual sobre os rumos da Universidade, em geral, e no Brasil, em particular. Humboldt, em seu projeto, respondia ao desafio de manter-se fiel ao ideário iluminista, sem entretanto negar o enraizamento numa identidade cultural nacional marcada pelo subjugo às tropas napoleônicas.

A modernidade contemporânea, marcada pela "globalização", lança desafios análogos. O ideário iluminista humboldtiano - de realizar uma formação ética da pessoa pela formação científica, universitária, é de grande atualidade. O crescimento, em nosso contexto, ao longo do século XX, em particular após a Segunda Guerra Mundial, da tecnociência no tecido institucional e nas práticas universitárias, torna hoje evidente a reflexão sobre o desafio político-filosófico. Ignorar esse desafio implica risco de consolidar a ameaçadora situação de crise de legitimidade da Universidade como instrumento de organização da cultura (BARTHOLO, 2001).

\section{Interdisciplinaridade - atualidade de um velho debate}

Em torno do debate sobre os rumos da Universidade, poucos temas têm tido tanta referência, no Brasil e no mundo, como o da interdisciplinaridade. Embora não se trate de uma questão nova, ela é de grande atualidade. Buscar, no passado, referências à importância da integração de conhecimentos, seria voltar à própria raiz da codificação dos saberes, antes mesmo da institucionalização da Universidade. É, sem dúvida, quando a especialização vai se tornando prática hegemônica, que a reação de alerta para a necessária capacidade de se integrarem partes aparece.

Wilson (1998, p. 8) cita William Whewell (1840) como um precursor do conceito de "consiliência", que seria uma forma de agregar/integrar "conhecimentos, ligando fatos e teorias ligadas a fatos através de disciplinas, de modo a criar uma base comum de explicação".

Alguns cruzamentos disciplinares vão se tornando necessidades evidentes, diante da incapacidade de se responder a questões inquietantes da atualidade. O tema da bioética, por exemplo, é lembrado como um mal-estar da modernidade que envolve, por um lado, cientistas vinculados a um campo em notável expansão nas ciências da vida e, por outro, ponderações que emanam das humanidades. Termos atingido o patamar das possibilidades de modificação e de 
criação de formas de vida revigora reflexões como as que Bronowski ${ }^{1}(1972,1978)$ lançara quando de seu desencanto diante das implicações da capacidade humana em destruir a vida na Terra, que se evidenciou com a bomba de Hiroshima. Tal debate se dinamizou ao longo da década de 1970, quando a crise do petróleo projetou o nuclear como opção energética e quando a "questão ambiental" ganhou importância no cenário mundial.

Alertas já se percebiam, também na leitura de autores "rebeldes", contestadores do modo de vida que se consolidou no mundo industrial ocidental após os chamados "trinta anos gloriosos", que marcaram o ciclo virtuoso da economia após a Segunda Guerra Mundial. O consumismo, o desperdício de energia e de matéria prima, a exclusão de significativas parcelas da população mundial, a degradação ambiental, a lógica da necessária destruição (via guerras) de capital material acumulado, como catapulta do crescimento, a cada vez mais rápida obsolescência de produtos e técnicas, dentre outros aspectos, provocaram uma onda de reação ao modo como a tecnociência evoluía. Ivan Illich apontou para a incoerência entre o acúmulo de conhecimentos desnecessários, veiculados pela educação formal, e a necessidade de saberes não ensinados nas escolas ("a sociedade desescolarizante"). Schumacher chamou a atenção para o fato de que a ciência e a tecnologia estavam seguindo um rumo em que cada vez mais o homem estava se valendo de conhecimentos complexos para o enfrentamento de problemas simples, desaprendendo as fórmulas tradicionais consagradas ("Small is beautiful"). No esteio dessa corrente, uma maré de trabalhos apareceu na década de 1970, estendendo-se à de 1980, gravitando em torno de conceitos como o de "tecnologias apropriadas ou alternativas", que pudessem levar a um desenvolvimento mais humano e parcimonioso ("ecodesenvolvimento"). Nesse último grupo, destacam-se autores como Sachs (1986, 1993).

Edgar Morin lançou uma importante luz sobre as questões que conduzem ao debate sobre a interdisciplinaridade, ao apresentar sua visão sobre a complexidade. Sua vasta obra, em particular a série $O$ método, tem a pretensão de lançar novas bases epistemológicas que devolvam à ciência sua capacidade de lidar com problemas complexos, de forma integral e não fragmentada em disciplinas que não se falam entre si.

Enfim, de modo grandioso e terrível, eis que neste fim de século [século $\mathrm{XX}]$ os problemas da vida e da morte surgem para o homem em termos fundamentais e globais. Atingimos o estágio supremo dos meios de transformação, a subjugação e a destruição da vida, e a questão da responsabilidade humana em relação à vida já não pode ser parcelada e dividida. (MORIN, 1980, p. 394)

Em trabalho mais recente, Morin (2004) retoma idéias que já haviam sido lançadas em estudos anteriores (MORIN, 1999, 2000). O autor associa o imperativo da reforma da educação com a necessária reversão da tendência de fragmentação do conhecimento em disciplinas que não dialogam entre si e que, por isso, perdem a capacidade de enfrentar os problemas atuais.

Uma [...] reforma se impõe, a do espírito, que permitiria aos homens enfrentar os problemas fundamentais de suas vidas privadas e de sua vida

\footnotetext{
${ }^{1}$ O físico Jacob Bronowski foi membro ativo do Projeto Manhattan, que resultou nas bombas lançadas sobre Hiroshima e Nagasaki, em 1945. A partir de então, e diante da sua perplexidade com a magnitude do impacto do artefato que ajudara a construir, dedicou-se à reflexão, expressa em vários livros, sobre os limites éticos da ciência.
} 
social. Esta reforma pode ser conduzida pela educação, mas infelizmente nosso sistema de educação deveria ser previamente reformado, pois ele está fundado sobre a separação: separação de saberes, de disciplinas, de ciências e produz espíritos incapazes de interconectar os conhecimentos, de reconhecer os problemas globais e fundamentais, de enfrentar os desafios da complexidade. Um novo sistema de educação fundado sobre o espírito de ligação, radicalmente diferente, portanto, do que existe atualmente, deveria ser um substituto. Este sistema poderia favorecer as capacidades do espírito em pensar os problemas globais e fundamentais da pessoa e da sociedade em sua complexidade. [...] Um tal sistema de educação poderá e deverá desempenhar um grande papel civilizador. Reforma da educação e reforma do pensamento se estimulariam reciprocamente, num círculo virtuoso (MORIN, 2004, p.193-4).

Vale ressaltar que não se limita ao campo das ciências humanas e sociais a reação contra a fragmentação das ciências e seu inevitável corolário - a falta de diálogo entre as diferentes disciplinas. $\mathrm{O}$ caso de Bronowski não foi isolado [cf. rodapé anterior].

Drummond (2004) identifica, em seu estudo sobre a obra de um conjunto de sete cientistas anglo-saxões ${ }^{2}$, uma postura de cautela quanto aos limites da visão segmentada. Sua análise chama a atenção para o preconceito corrente nas ciências sociais, quanto ao distanciamento dos cientistas das áreas naturais e biológicas em relação à dimensão humana da questão ambiental. Evocando a contribuição interdisciplinar dos autores estudados, são identificados importantes elementos de conexão entre os enfoques contidos naqueles trabalhos consagrados e questões que são objeto de investigação socioambiental. A conclusão é que os diferentes campos disciplinares deveriam se conhecer mais, reciprocamente.

Dirigindo-se aos cientistas sociais sintonizados com o socioambientalismo, Drummond (2000, p. 41) argumenta que é necessário abrir espaços onde a interdisciplinaridade ou, pelo menos, um trabalho conjunto entre disciplinas, se torne possível: "enquanto os cientistas sociais queremos entender a paisagem natural em que os humanos habitam, os cientistas naturais querem entender os humanos que habitam a paisagem natural". As limitações das instituições científicas brasileiras e internacionais, inclusive das agências financiadoras de pesquisa, que "ainda têm estrutura integralmente disciplinar", são apontadas no texto.

Analogamente, ainda que focando essencialmente questões atinentes às ciências da natureza, em particular a biologia evolutiva, Wilson (1998) identifica os limites dos recortes disciplinares. A imagem de uma totalidade com pontos que sobressaem com clareza, circundados por espaços em branco, desconhecidos, é apresentada pelo autor. Nela, mesmo os pontos conhecidos não conseguem perceber os demais, em função dos espaços entre eles. O livro Consilience trata desses espaços (gap analysis). Entre as lacunas com mais potencial de exploração atualmente estariam a física, a reconstrução de células vivas, a organização de ecossistemas, a co-evolução de genes e cultura, as bases físicas da mente e as profundas origens da ética e da religião.

A proposta de Wilson - "consiliência" - é apresentada com cautela. "Se a visão de mundo da "consiliência" é correta, a travessia dos espaços em branco [gaps] será uma viagem de Magalhães que no futuro circundará a realidade como um todo" (WILSON, 1998, p. 268). Mas, como na viagem de Magalhães, trata-se de uma rota exploratória de risco: "A exploração pode se

\footnotetext{
${ }^{2} \mathrm{O}$ texto focaliza as contribuições mais antigas de sete cientistas que são referência consagrada como descobridores ou formuladores das grandes questões ambientais dos últimos 70 anos (Paul Sears, Aldo Leopold, Rachel Carson, Paul Ehrlich, Donella Meadows, Garrett Hardin e James Lovelock).
} 
dar num mar interminável [...]" (WILSON, 1998). Serão necessárias, segundo o autor, algumas décadas para que se confirme qual das duas imagens será efetiva: a da "circunavegação" ou a do "mar infinito". Em todo caso, como conclui Wilson, em ambas as circunstâncias, só teremos conhecido uma fração infinitesimal dos detalhes internos da existência material. Portanto, o enfoque da "consiliência" precisará se nutrir do avanço do conhecimento nos moldes como se dá nas instituições acadêmicas: "a exploração continuará numa profusão de disciplinas escolares" (WILSON, 1998). O enfoque proposto por Wilson teria efeito positivo sobre as disciplinas, em particular as que tratam da "existência material": as ambições das ciências naturais poderão ser vistas com maior clareza por monocientistas" (WILSON, 1998).

A fórmula epistemológica vislumbrada por Wilson é evidentemente biocêntrica. Nela as ciências biológicas têm posição central na busca de entendimento do que ele chama de "existência material". É uma contribuição relevante, por vir de um consagrado cientista da vida, mas avança pouco o debate sobre o redesenho institucional necessário à Universidade do século XXI. Serve, entretanto, de antídoto a teses finalistas, como a de Fukuyama ("O fim da história") e Horgan ("O fim da ciência"): ainda falta muito a aprender!

Mas se, por um lado, ainda falta muito a aprender, por outro, vai se tornando evidente que falta também aprender como aprender. A proposta de Wilson pode servir para (re)organizar alguns aspectos das ciências da vida, segundo ele sob a hegemonia da biologia, mas a questão é bem mais ampla e exige outras centralidades. Esse é um desafio que demanda reflexão.

\section{Sobre a imaterialidade e a volatilidade, e suas implicações na educação}

Um traço marcante da herança que o século XX deixou para o XXI é a emergência do "imaterial" como objeto econômico e como fenômeno que redesenha o modo de vida e abre novos espaços no âmbito da cultura, da ciência, da educação, da economia, das relações sociais, no acesso à informação, dentre outros. Para se ter uma idéia da magnitude econômica dos setores "imateriais" (telefonia, computadores-internet, televisão), Passet (2000, p. 228) assinala que tais atividades já são responsáveis por um terço do PIB norte-americano, incluindo-se o comércio eletrônico. Seria miopia não considerar o impacto dessas mudanças sobre a educação, tanto em termos de novas formações (produtos), como nas técnicas pedagógicas (processos).

A volatilidade do ciclo de vida das técnicas (e dos produtos, entendendo-se estes tanto como os "recursos humanos" qualificados, quanto a produção material e imaterial de bens e serviços), bem como a rapidez com que a ciência avança sobre novos patamares colocam em cheque os sistemas de educação. Isso se dá tanto nos aspectos de forma - que se estruturou para produzir competências para profissões tidas como perenes - como nos de conteúdo - que seguiu uma rota "especializante".

Gorz (2003, p. 57) chama a atenção para o fato de que a economia se inclina cada vez mais para a dimensão imaterial, que tem como fundamento o caráter cognitivo, que é de difícil mensuração. Ao mesmo tempo, nos templos da produção do conhecimento (as universidades e os institutos de pesquisa) tal revolução econômica (e científica) não é acompanhada por reformas institucionais compatíveis. O conservadorismo destas instituições contrasta com o rápido ritmo de transformação dos modos de produzir valores (materiais ou não). Nesse sentido, a Universidade, quase milenar, perde para laboratórios privados, que têm um modo de gestão bem mais flexível e adaptativo. Com isso, perde-se também o que de melhor a Universidade tem a 
oferecer, que é a universalização dos saberes, em termos de socialização e de abrangência. Diferentemente dos laboratórios privados, que evoluem no sentido de agregarem a produção de ciência ao seu papel tradicional de geração de tecnologia, é nas universidades que se dá o avanço em campos que não estão necessariamente ligados à produção de valores de troca, como a filosofia, as artes e as humanidades em geral. Nesse contexto, duas tendências indesejáveis podem ser vislumbradas, ambas implicando riscos específicos:

- A Universidade busca se adaptar ao pragmatismo de mercado, criando linhas de produção de ciência e tecnologia segundo a lógica de demandas de "clientes". O risco maior, nesse caso, é o da valorização das atividades de mercado, em detrimento do caráter de universalidade.

- A Universidade se fecha na "tradição" de sua organização fragmentada, cristalizando um modus operandi em que seus sub-sistemas se autonomizam em relação ao sistema como um todo, num movimento caótico. Nesse caso, o risco principal é o embotamento, com inevitável isolamento e perda de legitimidade de seu papel e de suas práticas.

Em ambos os casos, o resultado é negativo e amplia o hiato entre o mundo acadêmico e o mundo real. O Processo de Bolonha (ver boxe), em curso atualmente na Europa, é um bom exemplo de mobilização, no sentido de se encontrar uma resposta atual e plausível às duas possíveis tendências acima assinaladas. Estão sendo considerados, no novo formato proposto para a Universidade:

- Redução no tempo de formação - quando o debate sobre educação e formação de recursos humanos se inclina para o conceito de LLL (Lifelong Learning), no qual cada indivíduo deve estar em permanente processo de aprendizado, não cabe mais uma formação universitária tão extensa como nos tempos das "formações perenes".

- Mobilidade espacial - o profissional do século XXI deve estar adaptado ao imperativo de conhecer diferentes realidades, além de seu espaço nacional. Para isso, é parte de sua formação aprender em outros contextos territoriais.

- Mobilidade institucional - o processo de formação pode (e deve) se dar em diferentes instituições, possivelmente em países diferentes. Para tanto, as estruturas curriculares devem ser ao mesmo tempo compatíveis, flexíveis e com equivalência em disciplinas.

- Mobilidade disciplinar - a tradicional formação em carreiras "definitivas" deve ceder espaço às novas profissões, marcadamente bi ou multidisciplinares.

\section{Em síntese:}

- em tempos de problemas complexos, que fogem ao universo de percepção de uma disciplina especifica, há que se ampliar o caráter eclético das formações de base, "em nível de licença" (graduação);

- em tempos de graves mazelas tecnológicas, resultantes da adoção de processos produtivos que não levaram em conta aspectos que fugiam à racionalidade econômica de curto prazo (a "síndrome da vaca louca” é um exemplo disso); ${ }^{3} \mathrm{e}$

\footnotetext{
${ }^{3}$ Passet (2000), ao se referir às mazelas da busca de um "produtivismo" sem atentar para as conseqüências sobre a própria dinâmica econômica, provocando males como a "vaca louca", a peste porcina e a doença dos frangos, assinala que "a doença do homem louco se transmite à vaca". Em sua análise, fíca evidente o conflito de lógicas
} 
- em tempos de aprendizado permanente (LLL);

Fica evidente que o formato da Universidade está defasado, não mantendo sintonia com a modernidade. Está aberta a temporada para reformas.

\section{Elementos para uma reforma}

O objetivo aqui não é formular uma proposta de reforma da Universidade. Trata-se, tão somente, de lançar luz sobre um aspecto que deve fazer parte da agenda da reforma.

É digno de nota, ao se abordarem a relevância e a atualidade do tema interdisciplinaridade no contexto da reforma universitária no Brasil, a marcante presença de tal debate também no âmbito da profunda transformação por que passa a Universidade européia. A reorganização do conhecimento, que dá a tônica da mobilização de todo aquele continente em torno de um novo formato e de uma nova estrutura da formação superior, tem como um de seus princípios a ampliação dos espaços acadêmicos onde temas interdisciplinares possam ser tratados.

Este fenômeno [a reorganização do conhecimento] manifesta-se concretamente por duas tendências divergentes. Por um lado, assiste-se a uma diversificação e especialização crescentes do saber e ao surgimento de especialidades de investigação e de ensino cada vez mais avançadas e mais precisas. Por outro lado o mundo acadêmico necessita urgentemente de se adaptar ao caráter interdisciplinar dos campos abertos pelos grandes problemas da sociedade, como o desenvolvimento sustentável, os novos flagelos médicos, a gestão dos riscos, etc. No entanto, as atividades das universidades, particularmente em matéria de ensino, tendem a permanecer organizadas, e ainda muitas vezes compartimentadas, em função do quadro disciplinar tradicional (COMISSÃO DAS COMUNIDADES EUROPÉIAS, 2003).

\section{PROCESSO DE BOLOGNA}

Em 1998, países europeus deram início à discussão para criação do Espaço Europeu do Ensino Superior, até 2010. Em junho de 1999, chegou-se à Declaração de Bolonha, assinada por 29 ministros europeus da Educação. Os objetivos definidos naquela Declaração foram confirmados em Praga, em 2001 e em Berlim, em 2003. Preconizam a adoção de uma estrutura de graus baseada essencialmente em dois ciclos (graduação e pós-graduação), que assumirão perfis e

inerente à falta de diálogo entre disciplinas. 
orientações diferentes, de acordo com objetivos individuais e acadêmicos e em função do exercício profissional e da empregabilidade.

De acordo com os entendimentos do Processo de Bologna, o ensino de graduação passa a se dar dentro de um prazo ideal de três anos, ou 180 créditos (podendo se estender em casos específicos, como medicina e engenharia). A pós-graduação fica estruturada em dois níveis: o mestrado, em dois anos, e o doutorado, para os que obtiverem o mestrado, em três anos.

O sistema ficou conhecido como 3-5-8 (anos) ou, na versão francesa, L-M-D (licença-mestradodoutorado). Uma das estratégias centrais do Processo de Bolonha, que a partir da reunião de Berlim em 2003 passou a contar com a adesão de 40 países europeus, é o reconhecimento, em todo o continente, dos créditos cursados em qualquer um dos países signatários. Com isso, alunos de um determinado curso podem cursar disciplinas em outro país. Um sistema europeu de créditos passa, então, a vigorar.

A relevância de se avançar na interdisciplinaridade, como forma de alcançar excelência, e a busca de novas formas de financiamento da Universidade, envolvendo parcerias com a iniciativa privada e o pagamento de taxas pelos alunos, são pontos de destaque no Processo de Bolonha.

Para alcançar a harmonização e a uniformização do sistema de ensino superior, a Declaração de Bolonha propôs os seguintes objetivos:

- competitividade do Sistema Europeu de Ensino Superior; e

- mobilidade e empregabilidade no Espaço Europeu.

Para chegar a esses objetivos, os países se comprometeram a:

- adotar sistema de graus e créditos comparável e facilmente inteligível;

- adotar sistema baseado essencialmente em dois ciclos, graduação e pós-graduação;

- promover a mobilidade de estudantes, docentes e pesquisadores; e

- dar uma dimensão européia ao ensino superior.

As duas tendências assinaladas -0 aumento da especialização e a necessária interdisciplinaridade - não são antagônicas, mas complementares. Quanto mais avança a especialização, mais importante se torna a construção de espaços de diálogo e integração de tais conhecimentos; e quanto mais complexos os problemas que inspiram o surgimento de tais espaços, mais necessário é o avanço de conhecimentos especializados a serem inseridos nas atividades interdisciplinares. É, portanto, uma relação dialética.

Desenvolver práticas interdisciplinares torna-se, de acordo com as análises que dão o rumo à reforma universitária européia, um pré-requisito à busca da excelência. Para tanto, é preciso uma nova construção institucional.

Uma [...] condição para atingir a excelência é que as universidades possam realizar mais trabalho interdisciplinar e sejam encorajadas a fazêlo. [...] a investigação avançada sai cada vez mais dos limites de uma 
única disciplina, em parte porque os problemas podem ser cada vez mais complexos, mas sobretudo porque a nossa percepção desse problemas evoluiu e temos agora maior consciência das diversas especializações necessárias para estudar as diferentes facetas do mesmo problema.

A organização do trabalho em base interdisciplinar exige das universidades uma organização flexível, por forma a que pessoas de departamentos diferentes possam partilhar os mesmos conhecimentos e trabalhar em conjunto, inclusive através de recurso às TIC. Exige também flexibilidade na forma como as carreiras são avaliadas e remuneradas, para que o trabalho interdisciplinar não seja penalizado por extravasar as estruturas departamentais normais. Por ultimo, exige que os próprios departamentos aceitem o trabalho "transfronteiriço" enquanto contributo aos objetivos da faculdade (COMISSÃO DAS COMUNIDADES EUROPÉIAS, 2003).

\section{Experiências interdisciplinares}

As experiências de institucionalização de estruturas interdisciplinares em universidades brasileiras se disseminaram bastante a partir da última década do século XX. Entretanto, não se pode limitar a análise a este período. Casos notáveis e bem sucedidos ocorreram, sobretudo a partir dos anos 1970.

A criação dos cursos de mestrado em Planejamento Urbano e Regional, apoiados por induções governamentais diretas, deve ser vista como referência. Naquele período, a Universidade brasileira passava por uma "reforma" que seguia uma tendência internacional: implantação de sistema de departamentos e créditos, com autonomização dos alunos em relação às turmas e desconcentração dos campi (uma reação ao movimento estudantil de 1968). Tal reforma obedecia, em nosso caso, a diretrizes políticas que transcendiam a esfera da educação (Acordo MEC-Usaid e Decreto 477).

A natureza interdisciplinar - embora à época esta não tenha sido uma questão que mobilizasse debates ou mesmo oposições - é uma característica dos programas de pós-graduação em Planejamento Urbano e Regional. O fato de surgir dentro de um contexto de mudanças institucionais, com forte conteúdo repressivo e desmobilização dos debates, pode ter favorecido a criação daqueles cursos. Mas há que se considerar também que o desenho institucional adotado não implicava expectativa de interação com outros departamentos. Na prática, tratava-se simplesmente de novos departamentos, dentro de uma estrutura matricial simples, na qual diferentes unidades formavam conjuntos (institutos, centros, faculdades), cujos elementos mantinham entre si autonomia. A migração (definitiva ou parcial) de docentes dos departamentos disciplinares para os novos cursos interdisciplinares não chagava a ser um mal-estar: geralmente, cada programa tinha seu próprio corpo de professores. Portanto, embora multidisciplinares na variedade de formação de seus docentes, aqueles programas passaram a desempenhar uma prática como se fossem uma disciplina em si: uma "disciplina interdisciplinar".

Ao longo do tempo, os cursos de Planejamento Urbano e Regional foram se consolidando, sobrevivendo bem ao fim da indução governamental. A constituição como uma área do 
conhecimento em si é confirmada pela criação de colegiados de avaliação ${ }^{4}$ específicos, no âmbito da Capes e do CNPq.

Há outras experiências que também podem ser evocadas, ao se analisarem trajetórias que merecem ser registradas como precursoras do debate sobre institucionalização da interdisciplinaridade. É o caso de cruzamentos tipicamente "bi-disciplinares", como a engenharia biomédica.

O surgimento de programas voltados ao meio ambiente e desenvolvimento sustentável e, mais recentemente, de gerontologia reproduz em parte a experiência do Planejamento Urbano e Regional. Mas encontra um ambiente institucional bastante diverso do dos anos 1970. Não ocorre em momento de reforma, portanto em clima favorável a novidades; não se dá pela criação de novos departamentos, mas sim pela busca de convergências entre estes; na inexistência de formas de contratação de novos docentes (no caso das IFES), crescem e aparecem "aliciando" professores de outros departamentos. Esse último aspecto, aliás, uma espécie de "fagocitose intra-institucional" é fonte de graves reações desfavoráveis, por parte da estrutura tradicional das universidades.

Avaliando com mais profundidade o processo que caracteriza a nova onda de surgimento de novos programas de pesquisa e pós-graduação interdisciplinares, percebe-se um conjunto de gargalos que são típicos e recorrentes em diferentes instituições. ${ }^{5}$ Entretanto, a despeito de todos os gargalos, o crescimento do conjunto de programas multidisciplinares, no âmbito do processo de avaliação de cursos da Capes, tem sido notável, não apenas em termos quantitativos, mas também como proporção do universo da pós-graduação.

Segundo dados da Capes (2004), entre 1996 e 2004, a evolução do número de cursos de mestrado e doutorado avaliados pela área multidisciplinar se deu em ritmo intenso: 25 mestrados e 7 doutorados em 1996 e 130 mestrados e 32 doutorados em 2004. No mesmo período, o total de cursos avaliados em todas as áreas, passou de 1083 para 1959 mestrados e de 541 para 1034 doutorados. Enquanto a taxa geométrica de crescimento anual dos curso de mestrados, em geral, foi de $8,3 \%$, a dos multidisciplinares foi de $24,9 \%$. No caso do doutorado, o incremento anual foi de $9,1 \%$ para o conjunto de cursos e de $24,9 \%$ para o grupo interdisciplinar.

De acordo com dados apresentados no documento Plano Nacional de Pós-Graduação (PNPG) 2005-2010 (CAPES, 2004), as estimativas de crescimento da pós-graduação brasileira apontam a grande área Multidisciplinar e Ensino ${ }^{6}$ como a que terá o maior incremento no período: enquanto o sistema como um todo deve ser ampliado em $76 \%$, a taxa esperada para o grupo no qual se situam os programas interdisciplinares é de $122 \%{ }^{7}$

\footnotetext{
${ }^{4}$ Os colegiados de avaliação são identificados pela sigla CA, que no CNPq significa Comitê Assessor e na Capes Comissão de Área.

5 A esse respeito, ver Bursztyn (2005). Ali, são apontadas essas dificuldades como síndromes. Uma delas é a das "vacas magras", que se caracteriza pela rejeição ao novo não pelo que ele representa, mas pelo fato de que, em aceitando, os parcos recursos (humanos e financeiros) teriam necessariamente de ser divididos.

${ }^{6}$ Em 1999 a Capes criou uma comissão especial para avaliar cursos que não se enquadravam em nenhuma das 8 grandes áreas e 44 sub-áreas do conhecimento que compõem a estrutura do sistema de avaliação. A idéia foi abrir um espaço para o crescente número de programas que fugiam à divisão tradicional em compartimentos ou que não eram assimilados ou acolhidos pelas comissões para as quais eram enviados. A nova comissão de área então criada reuniria o conjunto de "multi"disciplinares e um grupo de cursos que, pela sua natureza, é de enquadramento problemático nos campos disciplinares: o ensino de ciências, que não trata exclusivamente de ciência pura nem apenas de educação.

${ }^{7}$ Considerando a equivalência estatística de 1 mestrado $+0,6753$ doutorado.
} 


\section{Arranjos institucionais}

Ao deixar a função de reitor da Universidade de Brasília, em 1989, Cristovam Buarque apresentou um relatório inusitado. Ao invés de simplesmente elaborar uma prestação de contas a seu sucessor, produziu um relato do que não tinha feito, uma agenda do que entendia como necessário ao redesenho da universidade. Uma visão algo pessimista se depreendia da leitura, que previa anos difíceis para a instituição, caso mudanças ousadas não fossem empreendidas: "os próximos anos serão anos de um necessário heroísmo ou de uma contínua decadência à morte [...]” (BUARQUE,1989, p. 4).

Em sua gestão, coerente com a percepção da necessária mudança, a Universidade de Brasília experimentou um processo inovador que, entretanto, não teve a devida continuidade. O projeto de Buarque era mudar o foco da defesa corporativa para uma prática sintonizada com os problemas da sociedade. Nesse sentido, o saber, que tem na Universidade seu maior suporte, deveria adquirir nova dinâmica, orientando-se aos complexos problemas do mundo. Isso exigiria, por um lado, seduzir a comunidade acadêmica para o projeto e, por outro, instituir mecanismos capazes de acolher as iniciativas inovadoras. $\mathrm{O}$ modelo adotado assentava-se sobre uma matriz em três dimensões. Cada membro da comunidade universitária (docentes, discentes e pessoal técnico-administrativo) ficaria vinculado a três níveis de organização: um departamento disciplinar, uma atividade lúdica (por exemplo, o coral universitário) e um núcleo temático multidisciplinar. O Centro de Estudos Avançados Multidisciplinares (CEAM), criado naquela época, sobrevive, uma década e meia depois. Mas com um papel relegado a um segundo plano na estrutura efetiva de funcionamento da universidade.

As mesmas dificuldades encontradas na materialização dos núcleos mutidisciplinares da UnB se reproduzem em outras instituições universitárias. Parece haver uma descrença das estruturas decisórias quanto à relevância da existência dos espaços acadêmicos não vinculados à lógica disciplinar. É como se ali se produzisse ciência de segunda classe ou se os que buscassem tal vinculação o fizessem por diletantismo, incompetência ou exotismo.

O surgimento dos programas ambientais interdisciplinares foi marcado por estes estigmas. Primeiramente, surgiu o Programa de Ciências Ambientas a USP, seguido pela criativa iniciativa de universidades nordestinas, que instituíram o que pode ter sido o primeiro caso de programa em rede do Brasil (Programa de Desenvolvimento e Meio Ambiente do Nordeste). Logo, surgiram os doutorados em Meio Ambiente e Desenvolvimento (UFPR) e em Desenvolvimento Sustentável (UnB), que foram seguidos por um amplo grupo de iniciativas, em várias universidades.

O traço em comum entre todos eles é a ousadia em abrir um espaço acadêmico novo, dentro de um contexto adverso ao surgimento de novas atividades: falta verba, faltam instalações físicas, falta pessoal. Por outro lado, a trajetória de cada um revela arranjos criativos que merecem análise em profundidade (BURSZTYN, 2005). Mas a característica mais marcante é o fato de todos recusarem a identidade de se tornarem mais um departamento: em todos os casos avaliados, o programa em questão é - e luta para ser - interdisciplinar e não departamental. Nesse sentido, não competem com a estrutura tradicional das suas respectivas universidades, constituindo uma outra dimensão no tecido institucional. 


\section{Conclusão: um modelo possível}

A partir das experiências vividas e avaliadas, é possível hoje identificar um modus de institucionalização condizente com a realidade do padrão geral de estruturação da Universidade brasileira. Sem interferir na dinâmica consolidada dos departamentos disciplinares $-\mathrm{D}_{\mathrm{s}}-\mathrm{e}$ das suas formas de aglutinação funcional (faculdades, institutos ou centros) $-\mathrm{C}_{\mathrm{s}}-$ as unidades interdisciplinares $-I_{s}-$ estariam situadas em outro plano organizacional (ver Figuras 1 e 2).

O Modelo em Estrela que se propõe permite ligações não entre os departamentos entre si, mas sim entre estes e as unidades interdisciplinares. Estas, por sua vez, devem ser formadas pela aglutinação de dois tipos de docentes e pesquisadores:

- um conjunto nuclear de profissionais ("core") com perfil e experiência no tema-objeto, vinculados essencialmente e por longo prazo ao Programa ; e

- membros de departamentos disciplinares que, embora identificados com a natureza e foco dos trabalhos, não deixam seus departamentos. Nesse caso, há uma "dupla lotação", mediante a qual as atividades de cada um se dividem entre a prática disciplinar (em torno de objetos que são tributários e passiveis e integração com os objetos interdisciplinares) e a vinculação parcial e não necessariamente perene aos trabalhos da unidade interdisciplinar.

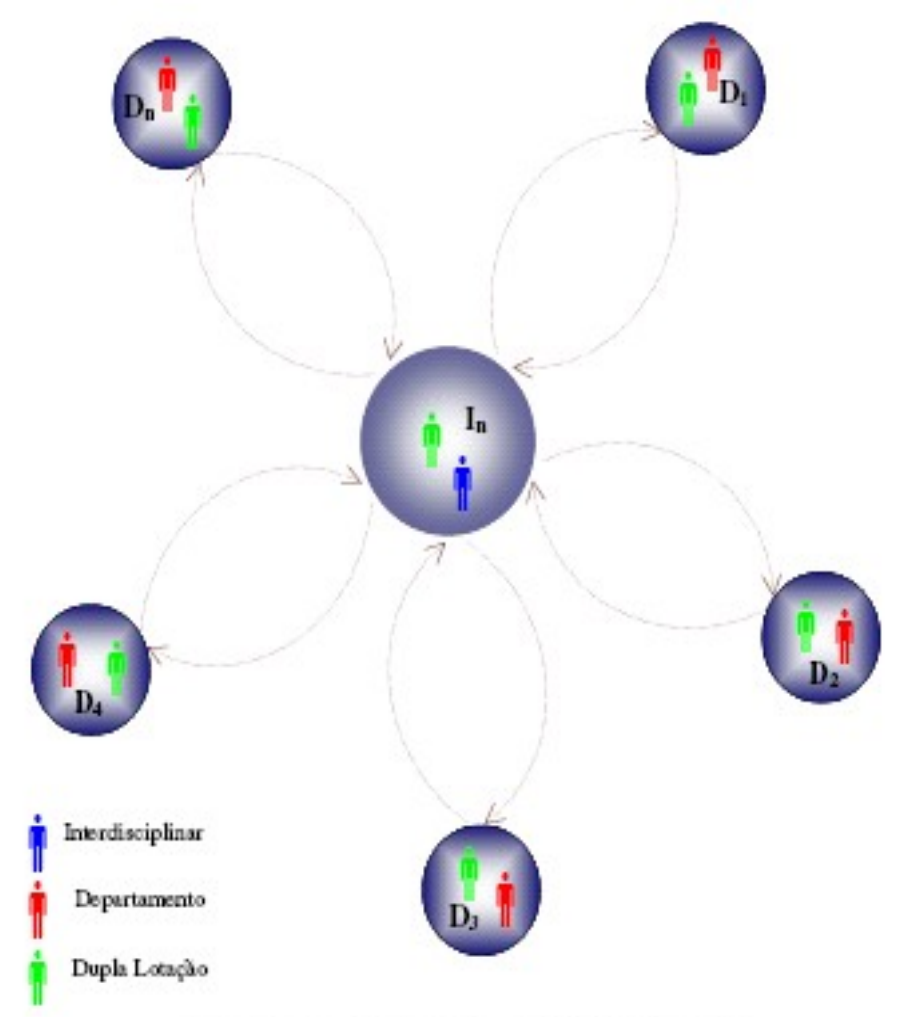

Figura 1 -Modelo Estrela - Esquema Simplificado 
A existência do core assegura a continuidade e a orientação geral das atividades. É de se esperar que tais membros do Programa sejam essenciais ao processo de integração das partes. Nesse sentido, seu perfil deve ser também de "generalista" - sem que isso implique abandono da identidade disciplinar originária. Como peça chave na integração, o conhecimento epistemológico e metodológico é atributo importante.

No caso dos membros em "dupla lotação", o papel esperado é o de ponte com o que se produz no âmbito de suas respectivas disciplinas e de alimentadores das práticas internas ao Programa interdisciplinar. Por sua dupla vinculação, sua produção científica deve ser creditada igualmente nas duas instâncias a que estejam vinculados. Não se trata de dupla contagem, mas apenas de efetiva consideração dos resultados de processos de aprendizado e geração de conhecimentos que se deve à interação dos dois níveis de vinculação.

No caso de programas que se envolvam em atividades interdisciplinares simples, como a "bidisciplinaridade", o arranjo pode ser reduzido a uma parceria que não envolve necessariamente a criação de uma nova instância institucional. Entretanto, tal procedimento implica riscos de descontinuidade e das atividades em parceria serem eclipsadas pelos focos prioritários dos departamentos de cada um.

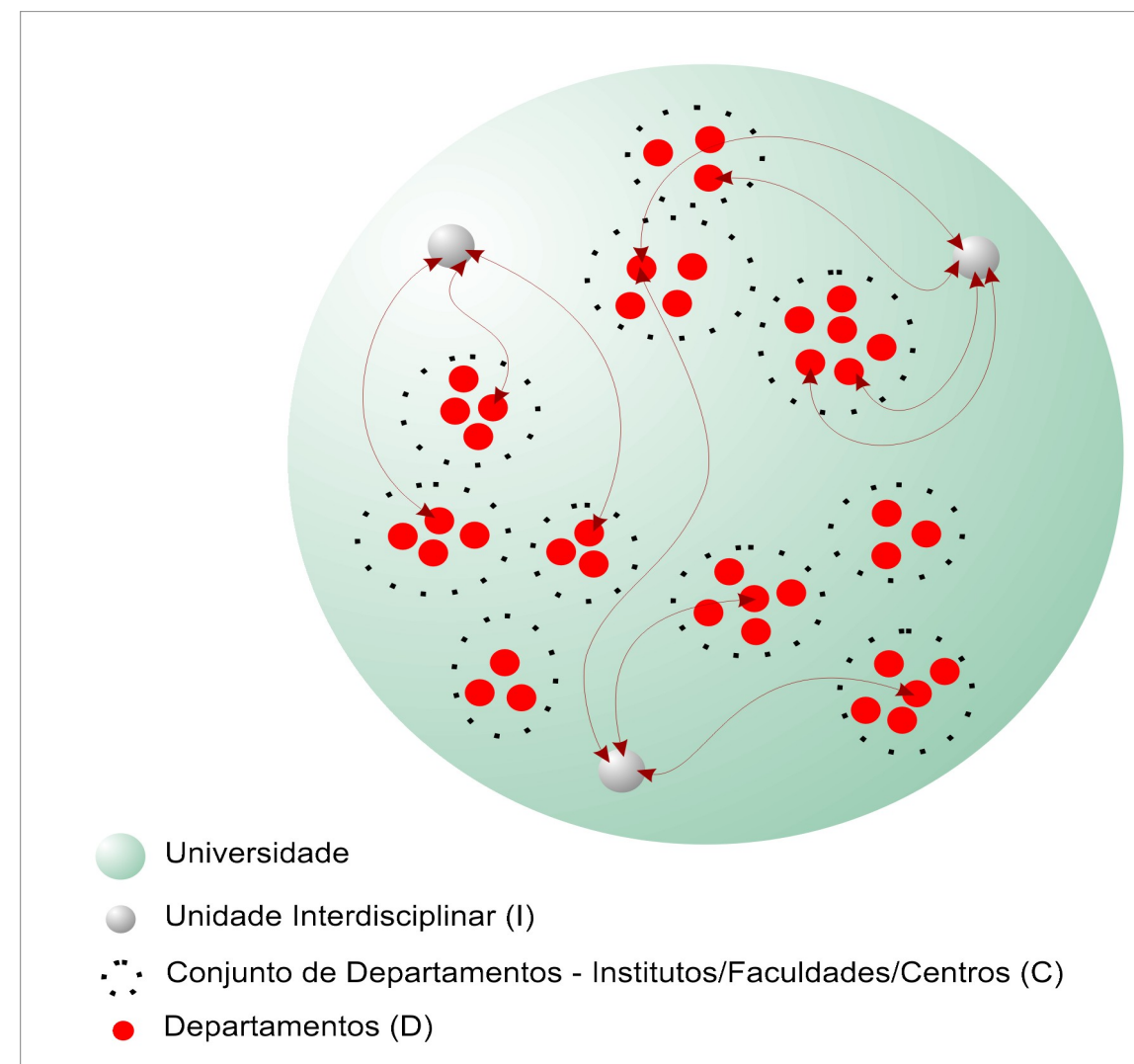

Figura 2 - Modelo Estrela - Na Estrutura da Universidade

Para efeito de representatividade, o Modelo Estrela permite a identificação de unidades acadêmicas interdisciplinares efetivas $\left(\mathrm{I}_{\mathrm{s}}\right)$ que devem ter assento nos colegiados, tanto em nível das respectivas universidades (conselhos e câmaras técnicas), quanto nos organismos de fomento 
(Capes e CNPq). De acordo com a prática atualmente vigente, as universidades tendem a abrir espaços em seus colegiados aos representantes de $\mathrm{D}_{\mathrm{s}}$ ou $\mathrm{C}_{\mathrm{s}}$, mas dificilmente aos de $\mathrm{I}_{\mathrm{s}}$. Isso provoca um ciclo vicioso de "deslegitimação" das unidades interdisciplinares.

No caso das agências de fomento, a experiência do $\mathrm{CNPq}$, que no inicio da década de 1990 instituiu um comitê multidiciplinar, não obteve sucesso. $\mathrm{O}$ colegiado em questão foi, na prática, um conjunto formado por membros de comitês disciplinares, que se reuniam ao final dos trabalhos de seus respectivos grupos. A composição era, nesse sentido, ad-hoc e não obedecia ao critério de perfil interdisciplinar. Por sua duvidosa legitimidade e baixa efetividade, ${ }^{8}$ a experiência foi logo abortada.

Já na Capes, a experiência que vem sendo construída após 1999 aponta para um aprendizado institucional que merece referência e aprimoramentos. O comitê assessor instituído tem a pretensão "multi"disciplinar, apesar de acolher iniciativas que são interdisciplinares. Sua composição é essencialmente disciplinar, embora ao longo do tempo possa ser notada uma ligeira tendência ao aumento em densidade da participação de avaliadores que são vinculados a programas interdisciplinares. Como em qualquer dos demais 44 comitês de áreas (disciplinas), é de se supor que também os programas interdisciplinares venham a ser avaliados por pares (peer evaluation).

A experiência da Capes em cinco anos de tratamento dos programas interdisciplinares no âmbito de um CA multidisciplinar já permite a inferência de um desenho institucional coerente com a fisionomia e a dinâmica dos respectivos cursos. Nesse sentido, a constituição de uma "grande área" interdisciplinar deve se dar, em substituição à atual multidisciplinar. Em termos operacionais, esta nova grande área seria subdividida em áreas, na medida em que certos conjuntos de programas temáticos se configurem como campos do conhecimento, com identidade própria e densidade, em termos quantitativos. A título de exemplo, Meio Ambiente e Desenvolvimento e Gerontologia assumiriam a configuração de áreas dentro da grande área Multidisciplinar. Programas ainda em fase de consolidação, em áreas ainda não institucionalizadas, ficariam vinculados a uma "área" interdisciplinar geral, espécie de incubadora de novas áreas. Quanto aos CAs interdisciplinares, sua composição deve se dar pela reunião de docentes vinculados aos programas avaliados nessas áreas. O conjunto pode ser paritário, com membros de dedicação integral aos programas $\left(\mathrm{I}_{\mathrm{s}}\right)$ e outros de dupla lotação (em $D_{s}$ e em $I_{s}$ ). A coordenação, entretanto, deve estar a cargo de representante efetivo de dedicação integral dos $\mathrm{I}_{\mathrm{s}}$.

A consolidação de trajetórias institucionais como a do Modelo Estrela pode servir, para que se instituam definitivamente mecanismos de representação dos Is, tanto nas universidades, quanto na cadeia de fomento-credenciamento-acompanhamento-avaliação. Além disso, permite também que se construam formas de interface dos $\mathrm{I}_{\mathrm{s}}$, que podem servir ao aprimoramento das práticas interdisciplinares.

Esse não é um desafio apenas no Brasil. Processos semelhantes estão em curso em todos os países onde o sistema universitário é regulado por mecanismos como os que o Brasil instituiu nas últimas três décadas. Temos de estar atentos ao quê de novo e exitoso esteja surgindo.

\section{Referências}

\footnotetext{
${ }^{8}$ Cabe assinalar que sendo cada membro também vinculado a uma área disciplinar, sua disposição em dividir suas quotas de recursos com os projetos interdisciplinares era bem pequena. Isso resultava em baixíssimo índice de aprovação das demandas.
} 
BARTHOLO, R.S. Solidão e liberdade: notas sobre a contemporaneidade de Wilhelm Von Humboldt. In: BURSZTYN, M. (Org.). Ciência, ética e sustentabilidade: desafios ao novo século. São Paulo: Cortez: Unesco, 2000.

BRONOWSKI, J. Science and human values. New York: Harper\&Row, 1972.

. The common sense of science. Cambridge: Harvard University Press, 1978.

BUARQUE, C. A aventura da universidade. São Paulo: Paz e Terra: Unesp, 1994.

. Ponto de partida: relatório da administração 85-89: o que falta fazer nas próximas décadas. Brasília: UnB,1989. Mimeografado.

BURSZTYN, M. Meio ambiente e interdisciplinaridade: desafios ao mundo acadêmico. Desenvolvimento e Meio Ambiente, Curitiba: Universidade Federal do Paraná, n. 10, p. 67-76, 2004.

COORDENAÇÃO DE APERFEIÇOAMENTO DE PESSOAL DE NÍVEL SUPERIOR. Programa Nacional de Pós-Graduação (PNPG): 2005-2010. Disponível em: < www.capes.gov.br >. Acesso em: 10 jan. 2005.

COMISSÃO DAS COMUNIDADES EUROPÉIAS. O papel das universidades na Europa do conhecimento. Bruxelas: CCE, 2003.

DRUMMOND, J. A. Ciência sócio-ambiental: notas sobre uma abordagem necessariamente eclética. In: ROLIM, Rivail Carvalho et al. (Org.). História, espaço e meio ambiente. Maringá: Anpuh-PR, 2000. Coletânea do VI Encontro Regional de História da Anpuh.

- Os cientistas sociais na construção da agenda ambiental contemporânea: uma participação retardatária e parcialmente equivocada. In: ENCONTRO ANUAL DA ANPOCS, 28., 2004, Caxambu.

FUKUYAMA, F. The end of history and the last man. New York: Maxwell-MacMillan, 1992.

GORZ, A. L'immatériel: connaissance, valeur et capital. Paris: Galilée, 2003.

HORGAN, J. The end of science. Reading: Addison-Wesley, 1996.

ILLICH, I. Deschooling society. Harmondsworth: Penguin, 1976.

MORIN, E. La Méthode 6: éthique. Paris : Seuil, 2004.

La tête bien faite. Paris : Sueil, 1999.

. Les sept savoirs necéssaires à l'education du futur. Paris : Seuil, 2000.

O método 2: vida da vida. Cintra: Europa-América, 1980.

PASSET, R. L'illusion néo-libérale. Paris: Fayard, 2000.

SACHS, I. Ecodesenvolvimento: crescer sem destruir. São Paulo: Vértice, 1986. 
. Estratégias de transição para o século XXI . In: BURSZTYN, Marcel (Org.). Para pensar o desenvolvimento sustentável. São Paulo: Brasiliense, 1993.

SCHUMACHER, E. F. O negócio é ser pequeno. Rio de Janeiro: J. Zahar, 1979.

WILSON, E. O. Consilience: the unity of knowledge. New York: Alfred A. Knopf, 1998. 